\title{
A novel sensitive immunoassay by nucleic acid barcode dot and its application in the detection of prostate-specific antigen
}

\author{
Xiao-Li Kong, Hui Qi, Han-Xin Zhou, Li-Li Ren, \\ Chong-Yan Deng and Fu-Rong Li* \\ Clinical Medical Research Center, The 2nd Clinic \\ Medicine College (Shenzhen People's Hospital), Jinan \\ University, Shenzhen, P.R. China
}

\begin{abstract}
Background: The sensitivity and selectivity of traditional methods limits ultramicro detection of proteins. Bio-barcode amplification detection methods based on nanotechnology enables ultramicro detection of protein. However, bio-barcode amplification detection depends on the oligonucleotides being fixed on a glass chip. It also requires specialized equipment, which limits its application. We introduce a nanonucleic acid barcode dot detection technology to determine ultramicro concentrations of protein. The method is simple, quick and accurate.

Methods: Magnetic probe (IgG-M) and dual-labeled gold nanoparticle bio-probe (IgG-Au-DNA) were prepared. Protein was captured using a sandwich assay technique and magnetic separation was used. The DNA barcode was released with dithiothreitol (DTT) and detected directly without the requirement for polymerase chain reaction (PCR). Serum prostate-specific antigen (PSA) from 135 patients was detected with this method and compared with enzyme linked immunosorbent assay (ELISA) and radioimmunoassay (RIA).
\end{abstract}

Results: Each IgG-Au-DNA could be covered with $138 \pm 47$ oligonucleotides and $11 \pm 3$ antibodies. The IgG-M could bind $118 \mu \mathrm{g}$ of antibody per mg. The sensitivity of nanonucleic acid barcode dot detection technology might allow detection of $1 \mathrm{fg} / \mathrm{mL}$. There were no significant differences in serum PSA from 135 patients when comparing the three methods (compared with ELISA, $\mathrm{r}=0.950$; and with RIA, $\mathrm{r}=0.967)$.

Conclusions: The nucleic acid barcode dot method does not require special equipment or complex procedures, but its detection limit is 2-3 orders of magnitude lower than ELISA.

Clin Chem Lab Med 2010;48:279-83.

\footnotetext{
*Corresponding author: Fu-Rong Li, Clinical Medical Research Center, The 2nd Clinic Medicine College, Jinan University, No. 1017 Dongmen North Road, Shenzhen 518020, Guangdong Province, P.R. China

Phone: + 86-755-25533018, Fax: +86-755-25533497,

E-mail: frli62@yahoo.com

Received August 17, 2009; accepted October 6, 2009;

previously published online December 10, 2009
}

Keywords: enzyme linked immunosorbent assay; nucleic acid barcode; prostate-specific antigen; radioimmunoassay; sensitive immunoassay.

\section{Introduction}

At present, techniques that use fluorescence labels and enzyme labels lack adequate sensitivity for early detection of cancer antigens and some neuropeptides (1-3). Although the sensitivity of detection using isotopes may reach 1 $\mathrm{ng} / \mathrm{mL}$, this requires special equipment and safeguards limiting its application (4).

Polymerase chain reaction (PCR) technology has been used for the amplification and detection of trace amounts of DNA (5). This technology can theoretically detect single stranded DNA and has good specificity (6). However, protein molecules are different from DNA molecules. The number of protein molecules cannot be increased using amplification techniques, which limits sensitivity (1). In 1992, Sano et al. (7) combined an immunoassay with PCR, creating a high sensitive detection technology, immuno-PCR. A specific DNA is attached to antibody using a joining molecule, and a corresponding relationship is established between antigen and DNA. Thus, protein detection equates to nucleic acid detection. However, the oligonucleotide ligation antibody technique is complex, and the number of oligonucleotides attached to antibodies is small, limiting sensitivity. In 2003, Mirkin et al. (8) amplified oligonucleotides on gold nanoparticle bio-probes using PCR. Ultramicro concentration of protein is measured by detecting the amount of oligonucleotides. However, this method is dependent on oligonucleotides being fixed on a glass chip requiring special equipment, which limits its application.

We introduce a method for ultramicro detection of protein based on nucleic acid barcode dot technology. Hydrosulfo, biotinylated oligonucleotide (Bio-ssDNA-SH) and rabbit anti-human prostate-specific antigen (PSA) polyclonal antibody were combined with gold nanoparticles $(30 \mathrm{~nm})$ to prepare dual-labeled gold nanoparticle bio-probes (IgG-AuDNA) (9). Magnetic micro-spheres are connected with PSA monoclonal antibodies to produce magnetic probes (IgG-M). IgG-M reacts with antigens in serum, IgG-Au-DNA is added, and then the antigen-antibody complex undergoes magnetic separation. Bio-ssDNA-SH on micro-spheres was diluted with dithiothreitol (DTT) and coated onto a nitrocellulose membrane. Bio-ssDNA is detected by the reaction of alkaline phosphatase-labeled streptavidin (SAAP). Detection of anti- 
A

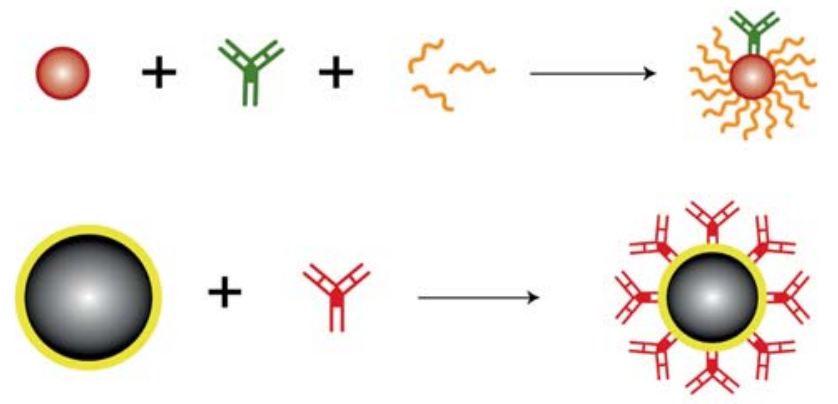

B

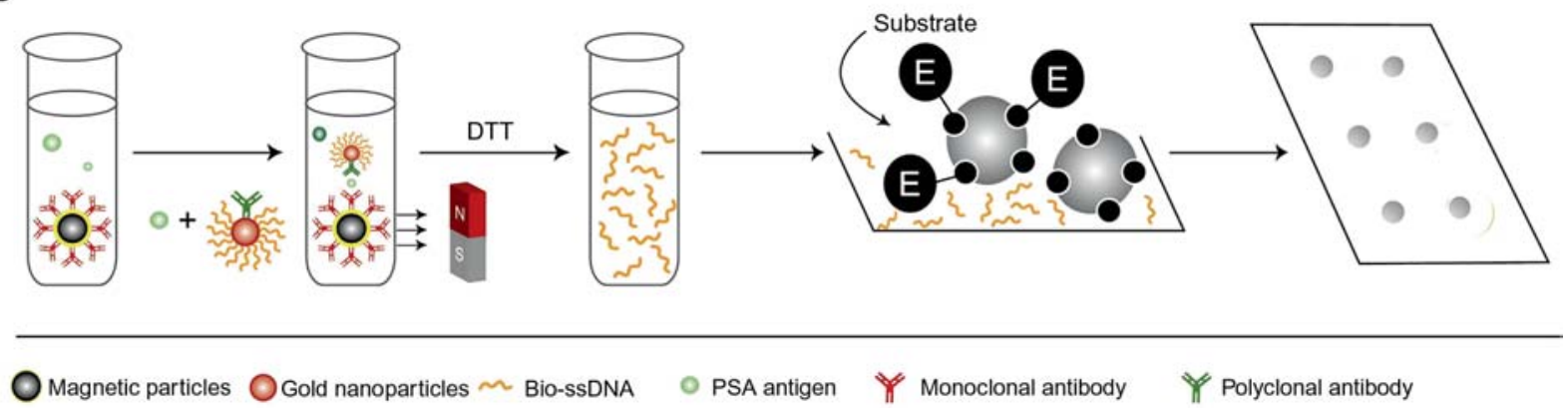

Figure 1 Nucleic acid code amplification assay.

(A) Preparation of the dual-labeled gold nanoparticle bio-probes and magnetic probe. (B) PSA detection scheme (DTT, dithiothreitol; E, enzyme).

gen is performed using nucleic acid barcode detection. Sensitivity to $1 \mathrm{fg} / \mathrm{mL}$ may be achieved without use of PCR (Figure 1). This method was used for the measurement of serum PSA and compared with enzyme linked immunosorbent assay (ELISA) and radioimmunoassay (RIA) methods.

\section{Materials and methods}

\section{Preparation of IgG-Au-DNA (9)}

Five $\mathrm{mL}$ of nano-gold colloid ( $3.5 \mathrm{nmol} / \mathrm{L}$ ) was adjusted to $\mathrm{pH} 9.0$ with $\mathrm{Na}_{2} \mathrm{CO}_{3}$. Goat antihuman PSA IgG $(35 \mu \mathrm{g})$ (Lab Vision Corporation, Fremont, USA) and $1000 \mu \mathrm{L}$ of $3^{\prime}$-terminal thiol-modified oligonucleotide $(13.2 \mu \mathrm{g} / \mathrm{mL}$, Shanghai Sangon Biological Engineering Technology Services Co. Ltd, Shanghai, China) were added and mixed for $3 \mathrm{~h}$ at $4^{\circ} \mathrm{C}$. Next, $500 \mu \mathrm{L}$ of phosphate buffered

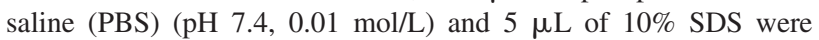
added and mixed for $30 \mathrm{~min}$. One $\mathrm{mL}$ of $\mathrm{NaCl}(1.2 \mathrm{~mol} / \mathrm{L})$ was gradually added and allowed to stand for $3 \mathrm{~h}$. Finally, $0.5 \mathrm{~mL}$ of $5 \%$ bovine serum albumin (BSA) was added and stored in the dark at $4^{\circ} \mathrm{C}$.

\section{Preparation of $\lg \mathrm{G}-\mathrm{M}$}

One hundred $\mathrm{mg}$ of sodium polymannuronate was dissolved in $4 \mathrm{~mL}$ of purified water and then $2 \mathrm{~mL}$ of $5 \% \mathrm{Fe}_{3} \mathrm{O}_{4}$ magnetic fluid (mean diameter: $200 \mathrm{~nm}$, The Research Institute of Micro/Nano Science and Technology, Shanghai Jiao Tong University, Shanghai, China) was added and mixed at $42^{\circ} \mathrm{C}$ followed by ultrasound for $15 \mathrm{~min}$. The mixture was adjusted to $\mathrm{pH} 10.0$ with $10 \% \mathrm{Na}_{2} \mathrm{CO}_{3}$, and heated to $60^{\circ} \mathrm{C}$. Using ultrasound and high speed stirring, the mixture was added to $90 \mathrm{~mL}$ of $\mathrm{AOT} /$ normal heptane oil at $60^{\circ} \mathrm{C}$ forming a transparent gray-black reverse microemulsion system. Using ultrasound and stirring, $4.5 \mathrm{~mL}$ of $30 \% \mathrm{CaCl}_{2}$ was added to the microemulsion, followed by magnetic separation, and then washing with acetone, alcohol and distilled water, respectively. Following centrifugation and vacuum freeze-drying, the resultant material was stored.

One mg of prepared magnetic spheres was removed, washed three times with phosphate buffer, and then $0.01 \mathrm{~mol} / \mathrm{L}$ PBS ( $\mathrm{pH} 7.0$ ) was added to produce a final volume of $4 \mathrm{~mL}$. Five $\mathrm{mg}$ of water soluble carbodiimide (EDC) and $7.5 \mathrm{mg}$ of sufl-NHS were added and mixed for $15 \mathrm{~min}$ at room temperature. Next, $50 \mathrm{mg}$ of 6-aminocaproic acid was added and stirred for $3 \mathrm{~h}$. We then added $600 \mu \mathrm{L}$ of PSA monoclonal antibodies ( $30 \mu \mathrm{g} / \mathrm{mL}$; Lab Vision Corporation, USA) followed by stirring for $6 \mathrm{~h}$, then sealed with $1 \mathrm{~mL}$ of glycine solution $(0.2 \mathrm{M})$ containing $0.2 \% \mathrm{BSA}$, and finally magnetic separation before storing at $4^{\circ} \mathrm{C}$. The shape was observed with a transmission electron microscope (TEM) and light microscope.

\section{Nucleic acid barcode dot detection method}

Forty $\mu \mathrm{L}$ of magnetic spheres $(5 \mathrm{mg} / \mathrm{mL})$, and $20 \mu \mathrm{L}$ of PSA standard solution was prepared by diluting $13 \mu \mathrm{g}$ of the PSA standard with PBS ( $\mathrm{pH} 7.2$ ) containing $0.2 \%$ BSA in a $1 \mathrm{~mL}$ volume at $10 \mu \mathrm{g} / \mathrm{mL}, 1 \mu \mathrm{g} / \mathrm{mL}, 100 \mathrm{ng} / \mathrm{mL}, 1 \mathrm{ng} / \mathrm{mL}, 10 \mathrm{pg} / \mathrm{mL}, 100 \mathrm{fg} / \mathrm{mL}$ or $1 \mathrm{fg} / \mathrm{mL}$, or $20 \mu \mathrm{L}$ of test serum diluted with PBS ( $\mathrm{pH} 7.2$ ) containing $0.2 \% \mathrm{BSA}$ to $1: 50$. These were incubated at $37^{\circ} \mathrm{C}$ for $1 \mathrm{~h}$ followed by magnetic separation, then washed three times with $0.01 \mathrm{~mol} / \mathrm{L}$ PBS ( $\mathrm{pH} 7.4$ ) containing $0.2 \% \mathrm{BSA}$, and then $80 \mu \mathrm{L}$ of gold nanoparticle probes $(10 \mathrm{nmol} / \mathrm{L})$ was added at $37^{\circ} \mathrm{C}$ for $1 \mathrm{~h}$ followed by magnetic separation, then washed three times with $0.01 \mathrm{~mol} / \mathrm{L}$ PBS ( $\mathrm{pH} 7.4$ ) containing $0.2 \%$ BSA. To a volume of 
$50 \mu \mathrm{L}, 5 \mu \mathrm{L}$ of DTT (Sigma Company, St. Louis, USA) was added to make the final concentration be $0.01 \mathrm{~mol} / \mathrm{L}$, DNA was dissociated for $3 \mathrm{~h}$ followed by magnetic separation and ultracentrifugation at $8944 \mathrm{~g}$ for $5 \mathrm{~min}$ at low temperature. Next, $10 \mu \mathrm{L}$ of separated DNA barcode was coated on a $5 \times 8 \mathrm{~cm}$ nylon membrane and baked at $60^{\circ} \mathrm{C}$ for $30 \mathrm{~min}$. SAAP (dilution 1:100; Lab Vision Corporation, USA) was then added and $30 \mathrm{~min}$ after reaction at room temperature, washed with $0.01 \mathrm{~mol} / \mathrm{L} \mathrm{PBS}(\mathrm{pH} 7.4)$ three times. This was followed by addition of NBT/BCIP (nitroblue tetrazolium/5-bromochloro-3 indole phosphate-4) in the dark for development for $20 \mathrm{~min}$. Superfluous water was absorbed and then allowed to dry. Visual assessment was used to compare dots. The dots can be analyzed with quantitative analysis software to calculate the amount of PSA by comparing the dot values from different standard samples. We calculated the mean value of three repeated square matrixes.

\section{Clinical serum specimens and PSA detection}

Serum was obtained from 45 patients aged 49-72 years (mean 61 years) diagnosed with prostate cancer by pathological examination; 45 patients with prostatic hyperplasia aged $51-70$ years (mean 58 years); 15 patients, eight men and seven women, with lung cancer $(n=6)$, rectal cancer $(n=5)$ or breast cancer $(n=4)$, aged 40-67 years (mean 53 years); and from 30 patients undergoing heath examination (18 men and 12 women) aged 40-65 years (mean age 50 years). All study methods were consistent with the Helsinki Declaration of 1975 as revised in 1996. Serum specimens were stored at $-80^{\circ} \mathrm{C}$ for future use. Serum was diluted with PBS $(1 \%$ BSA) to $1: 50$, and then $20 \mu \mathrm{L}$ was used. Testing was performed in triplicate. The background values obtained by nucleic acid barcode detection were compared with a standard band. PSA concentrations $>4 \mathrm{ng} / \mathrm{mL}$ were considered positive and PSA concentrations $\leq 4 \mathrm{ng} / \mathrm{mL}$ were considered negative to determine the specificity and sensitivity of nucleic acid barcode detection for serum PSA. The results obtained by nucleic acid barcode detection also were compared with those obtained with by ELISA (CanAg Diagnostic $\mathrm{AB}$, Gothenburg, Sweden) and RIA kit (CIS BIO Inc, France). Paired $\chi^{2}$-test was used in the test result analysis.

\section{Statistical analysis}

SPSS13 software was used for the statistical analysis of all data. Qualitative results were expressed as $\bar{\chi} \pm s$. The $\chi^{2}$-test was used to compare quantitative data. Statistical significance was established as $\mathrm{p}<0.05$. Since data were not normally distributed, Spearman correlation analysis was used for the results obtained by the nucleic acid barcode dot method, ELISA and RIA. The $\alpha$ value was set at 0.05 .

\section{Results and discussion}

\section{Characteristics of IgG-Au-DNA}

This method requires two types of probes. The IgG-Au-DNA probe has a diameter of $30 \pm 5 \mathrm{~nm}$ with uniform size assessed by TEM and laser light scattering (9). Gold nanoparticles may be stored in various types of buffer solutions because of changes in its stability which helps avoid false positive tests. The amount of IgG covering the gold nanoparticles can be detected using Coomassie brilliant blue (G-250) and calculated. The number of IgG molecules covering each IgG-

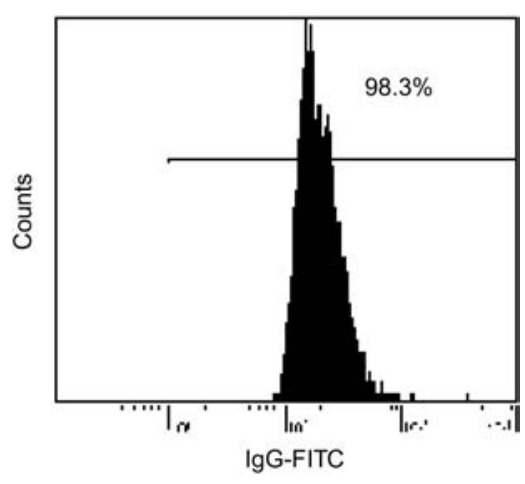

Figure 2 Immunoreactive antibodies in magnetic probes analyzed by flow cytometry.

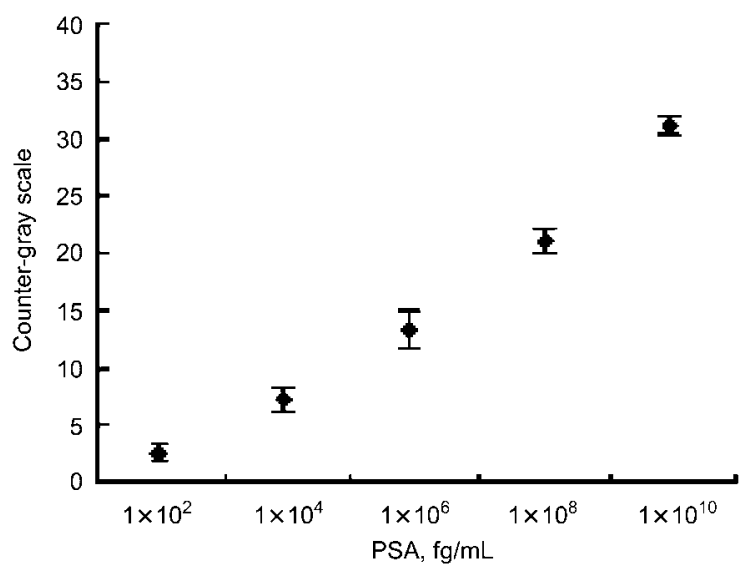

Figure 3 Standard curve for PSA analysis.

Au-DNA was $11 \pm 3$. Thiol-modified oligonucleotides combined with gold nanoparticles were used as target molecules. The number of nucleic acid barcode on each probe is important because detected nucleic acid barcodes were in direct proportion to measured signal. The number of fluorescin isothiocynate (FITC)-labeled and thiol-modified oligonucleotides on gold nanoparticles replaced by DTT were calculated with a fluorospectrophotometer. The maximum dose of oligonucleotide on $1 \mathrm{~mL}$ of gold nanoparticles is about $24.3 \mu \mathrm{L} / \mathrm{mL}(165 \mu \mathrm{g} / \mathrm{mL})$. The number of oligonucleotide on each gold nanoparticle was $138 \pm 47$.

\section{Characteristics of IgG-M}

The cross-linked antibody on the magnetic microsphere combines with antigen, followed by magnetic separation. However, the affinity interaction (such as antigen-antibody reaction) between biomolecules possesses steric specificity, and steric hindrance usually makes the separated biomacromolecules not able to bind with ligands resulting in poor separations efficiency. Therefore, 6-aminocaproic acid is used as an "arm" molecule to connect with the surface of microspheres. The "arm" is connected with antibodies by cross-linked EDC to prepare excellent magnetic microsphere 


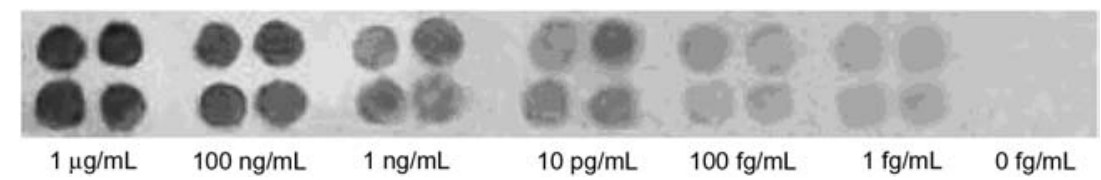

Figure 4 Diagram of PSA test standards on Nylon membrane (4 dots in each concentration).

probes. One milligram of magnetic micro-spheres may connect with up to $118 \mu \mathrm{g}$ of antibodies. Flow cytometry indicated that there were immunoreactive antibodies in $98.3 \%$ of the IgG-M (Figure 2). Big magnetic micro-spheres do not necessarily have good separation, and may yield false positive results. IgG-M with 200 nm-mean diameters can achieve good separation.

\section{Nano-nucleic acid barcode dot detection}

PSA was studied due to its important role in prostate cancer and breast cancer. In patients with prostate cancer, PSA level was very low following surgery. Also, PSA may be used as an indicator of tumor recurrence and response to chemotherapy (10). In addition, PSA is an important target in screening for breast cancer. Under normal conditions, serum PSA is much lower in women than in men. Ultra-sensitive test methods for PSA are important in screening and diagnosis of breast cancer (11). For detection of PSA, the molecule was captured using a sandwich method with IgG and IgG-Au-DNA. The compound underwent magnetic separation in solution. The DNA barcode was released with DTT and detected directly without the requirement for PCR. BiossDNA was detected with SAAP. The results were obtained by visual examination. At the same time, a standard curve from $1 \mathrm{fg}$ to $1 \mu \mathrm{g} / \mathrm{mL}$ (Figures 3 and 4 ) was produced, and PSA concentrations from $100 \mathrm{fg} / \mathrm{mL}$ to $1 \mu \mathrm{g} / \mathrm{mL}$ showed good linear relationship $(\mathrm{R}=0.9759)$. The sensitivity for analysis obtained from the standard curve was $1 \mathrm{fg} / \mathrm{mL}$. The semi-quantitative value of the specimen was determined by visual comparison of specimens with the standard curve. The

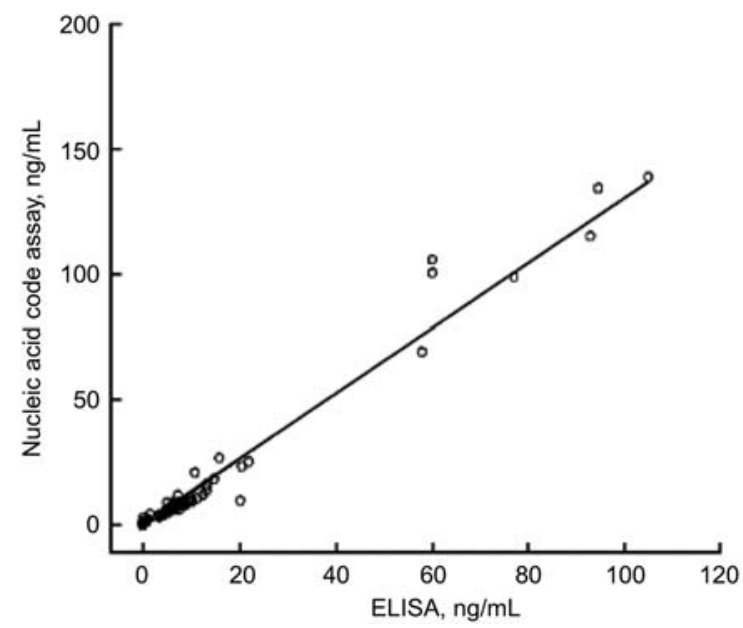

Figure 5 Correlation between nucleic acid barcode assay and ELISA. color scale of the specimens may also be analyzed with software to obtain the amount of PSA when one knows the DNA barcode in the antigen-antibody complex.

In this method, antigen was detected with two types of probes using nucleic acid fragment detection. On each IgG$\mathrm{Au}-\mathrm{DNA}$, protein combines with many oligonucleotides, and then combines with biotin-streptavidin which greatly increases the sensitivity of the method. The lower limit of PSA in this method was $100 \mathrm{fg} / \mathrm{mL}$, which is 1000 times more sensitive than ELISA. Compared with immunodetection (1 $\mathrm{ng} / \mathrm{mL}$ ), the method does not require specialized equipment and safeguards (12). Also, the method is simple and quick. Sensitivity is increased because of more effective capture steps and signal background is reduced because the DNA barcode is detected directly.

\section{Serum PSA detection}

Serum specimens from 135 cases (prostate cancer group, prostatic hyperplasia group, other tumor group and normal control group) were detected with our method, ELISA and RIA. PSA $>4 \mathrm{ng} / \mathrm{mL}$ was considered as positive and PSA $\leq 4 \mathrm{ng} / \mathrm{mL}$ was considered negative. $\chi^{2}$-test indicated $p>0.05$. There were no significant differences in PSA between the three methods at $\alpha=0.05$.

Since data were not normally distributed, Spearman correlation analysis was used for the PSA results obtained by nucleic acid barcode dot method, ELISA and RIA (Figures 5 and 6). Results indicated that the coefficient correlations (r) of nano-nucleic acid barcode dot detection method with ELISA and RIA were $0.950 \quad(\mathrm{p}>0.001)$ and 0.967 $(\mathrm{p}>0.001)$, respectively.

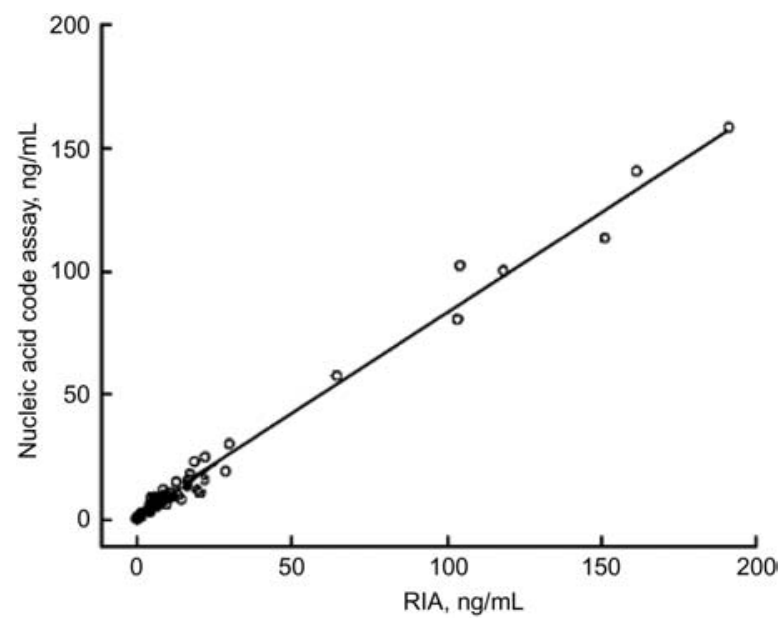

Figure 6 Correlation between nucleic acid barcode assay and RIA. 


\section{Conclusions}

An ultramicro detection method for protein was established using nucleic acid barcode as a marker. The number of DNA barcodes on bioprobes may be adjusted by the size and surface of the gold nanoparticles. The detection limit of this method is 2-3 orders of magnitude lower than ELISA. This method does not need special equipment or complex procedures. It only requires probes, magnetic separators and nylon membrane. Visual assessment or image analysis software can be used to obtain results with this method. We provide a technology for detection of ultramicro amounts of protein, with great potential for different applications.

\section{Conflict of interest statement}

Authors' conflict of interest disclosure: The authors stated that there are no conflicts of interest regarding the publication of this article. Research funding played no role in the study design; in the collection, analysis, and interpretation of data; in the writing of the report; or in the decision to submit the report for publication.

Research funding: The authors greatly appreciated financial support from Technology Project of Shenzhen (No.2004A110), Technology Project of Guangdong (No. 2006B14701001) and National 863 High Technology Project (No.2003BA310A23).

Employment or leadership: None declared.

Honorarium: None declared.

\section{References}

1. Georganopoulou DG, Chang L, Nam JM, Thaxton CS, Mufson EJ, Klein WL, et al. Nanoparticle-based detection in cerebral spinal fluid of a soluble pathogenic biomarker for Alzheimer's disease. PNAS 2005;102:2273-6.

2. Stoeva SI, Lee JS, Thaxton CS, Mirkin CA. Multiplexed DNA detection with biobarcoded nanoparticle probes. Angew Chem Int Ed Engl 2006;45:3303-6.

3. Stoeva SI, Lee JS, Smith JE, Rosen ST, Mirkin CA. Multiplexed detection of protein cancer markers with biobarcoded nanoparticle probes. J Am Chem Soc 2006;128:8378-9.

4. Larson SM, Carrasquillo JA, Reynolds JC. Radioimmunodetection and radioimmunotherapy. Cancer Invest 1984;2:36381.

5. Wu Y, Liu S, Li H. Electrochemical biosensing using amplification-by-polymerization. Anal Chem 2009;81:7015-21.

6. Bustin SA. Quantification of mRNA using real-time reverse transcription PCR (RT-PCR): trends and problems. J Mol Endocrinol 2002;29:23-39.

7. Sano T, Smith CL, Cantor CR. Immuno-PCR: very sensitive antigen detection by means of specific antibody-DNA conjugates. Science 1992;258:120-2.

8. Nam JM, Thaxton CS, Mirkin CA. Nanoparticle-based bio-bar codes for the ultrasensitive detection of proteins. Science 2003;301:1884-6.

9. Kong XL, Qi H, Li FR, Zhou HX. One-step preparation of antibody and oligonucleotide dual-labeled gold nanoparticle bio-probes and their properties. Biotechnol Lett 2008;30: 2071-7.

10. Yan Y. Intraindividual variation of prostate specific antigen measurement and implications for early detection of prostate carcinoma. Cancer 2001;92:776-80.

11. Black MH, Giai M, Ponzone R, Sismondi P, Yu H, Diamandis EP. Serum total and free prostate-specific antigen for breast cancer diagnosis in women. Clin Cancer Res 2000;6:467-73.

12. Chan CP, Cheung YC, Renneberg R, Seydack M. New trends in immunoassays. Adv Biochem Eng Biotechnol 2008;109: $123-54$. 